UDC: 821.134.2.09 Clarín L. A

821.134.2.09 Pardo Bazán E. DOI: https://doi.org/10.18485/hispserb.2019.2.ch14

\author{
Vladimir Karanović ${ }^{1}$ \\ Universidad de Belgrado \\ Serbia
}

\title{
EL IDEALISMO ESTÉTICO EN LOS TEXTOS CRÍTICO-LITERARIOS DE LEOPOLDO ALAS CLARÍN: UNA MIRADA CRÍTICA A LA OBRA DE EMILIA PARDO BAZÁN
}

\begin{abstract}
Resumen
Uno de los elementos esenciales de la actividad crítica de Leopoldo Alas Clarín (1852-1901) es el pragmatismo, que le lleva a practicar dos clases de crítica literaria: 1) la que no depende del humor en que se encuentra el escritor sino de las obras o autores examinados, que se puede denominar la crítica negativa puesto que se trataba de libros que carecían de valor artístico y de autores que se mostraban incapaces de salir de la vulgaridad, o sea, un tipo de parásitos de la vida literaria, crítica cuyo elemento principal era la burla, el ataque, "crítica higiénica y policíaca"; y 2) la que comprende un estudio minucioso, contiene claros elementos de simpatía y afición hacia los autores analizados, así que consecuentemente se puede denominar la crítica positiva. A pesar de la fama sobre la actividad crítica de Clarín, solo la segunda clase de crítica era apreciada y verdaderamente aceptada por el famoso realista español.

Los críticos y los novelistas del realismo español, entre los cuales destacamos a Leopoldo Alas Clarín, presentan una singular importancia en el campo de la recepción de un idealismo estético, proveniente del quijotismo pre-

\footnotetext{
11vkaranovic@gmail.com
} 
moderno, ya que con sus obras literarias y crítico-literarias muestran una vía evolutiva desde el mero estatus pro o contra las nuevas tendencias literarias de los escritores realistas hasta un idealismo estético y espiritual, característico para los últimos años del siglo XIX.

El objetivo principal del presente artículo es identificar, interpretar y explicar la presencia y la recepción del idealismo estético y su evolución en los textos crítico-literarios clarinianos dedicados a las obras de Emilia Pardo Bazán.

Palabras clave: Leopoldo Alas Clarín, Emilia Pardo Bazán, siglo XIX, crítica literaria, realismo español.

Un autor ilustre, que debía de saber lo que decía, advirtió que el agradecimiento con que los buenos escritores pagan al crítico que los alaba, es sentimiento frío; y tal creo yo, y estéril, porque es natural que la vanidad vea en los elogios más obra de la justicia y del propio mérito que de la benevolencia ajena; agradecer mucho en tales casos y llegar por el agradecimiento hasta el cariño es para muy pocos, porque los más se inclinan a pensar que cuanto más agradezcan más reconocen al favor y más niegan a los merecimientos propios. Por todo lo cual, sobrino mío, no esperes de la crítica el nacimiento de grandes y útiles amistades, ni amparo serio y constante en tus necesidades de los que favoresciste; espera, en cambio, odio eterno de aquellos a quien insultaste o alabaste menos que ellos quisieran.

Leopoldo Alas Clarín

\section{Introducción}

Para sus contemporáneos Leopoldo Alas Clarín (1852-1901) era profesor de derecho en la Universidad de Oviedo, un periodista de gran éxito $y$, ante todo, un respetado crítico literario, mientras su obra literaria (parcialmente con la excepción de La Regenta) fue víctima de su actividad crítica y objeto de valoraciones erróneas. Puesto que hoy día la importancia de la obra literaria clariniana ya ha sido confirmada y puesta en una posición especial dentro del sistema literario del realismo español, la inspiración de la valoración negativa y perpetuos ataques hay que buscarla en causas extraliterarias, en la crueldad de su pluma y la crítica del mundo literario de su época. Clarín dedica su actividad crítica a varios campos y materias de la actualidad española, pero se destacan sus críticas literarias, siendo uno de los críticos literarios más importantes entre los realistas y naturalistas españoles (Karanović 2018: 320-321). 
Sus textos sobre la crítica literaria han sido reunidos y minuciosamente editados en varios tomos, titulados: Solos de Clarín (1881), La literatura en 1881 (1882), Sermón perdido (1885), Nueva campaña (1887), Mezclilla (1889), Ensayos y Revistas (1892), Palique (1894), Siglo pasado (1901).

Se pueden detectar tres modos en la actividad crítica de Clarín: el negativo (satírico), el afirmativo (panegírico) y el interpretativo (exegético). Gonzalo Sobejano (1991: 40) explica que

[e]l primero (...) acusa el error para hacer sentir, de manera indirecta, la necesidad de la verdad; su finalidad es moral: sanear el ambiente. El modo afirmativo, al contrario, pone de relieve lo más valioso, con la intención de crear entusiasmo y propagar estímulos. El modo explicativo, en fin, reconoce detenidamente su objeto, lo analiza y lo enjuicia con equilibrio, pretendiendo discernir su significado o razonar su oportunidad.

Además, uno de los elementos esenciales de su actividad crítica es el pragmatismo, que le lleva a practicar dos clases de crítica literaria: 1) la que no depende del humor en que se encuentra el escritor sino de las obras o autores examinados, se puede denominar la crítica negativa, puesto que se trataba de libros que carecían de valor artístico y de autores que se mostraban incapaces de salir de la vulgaridad, o sea, un tipo de parásitos de la vida literaria, crítica cuyo elemento principal era la burla, el ataque, "crítica higiénica y policíaca" (Beser 1968: 68-69); 2) la que comprende un estudio minucioso, contiene claros elementos de simpatía y afición hacia los autores analizados, así que consecuentemente se puede denominar la crítica positiva. A pesar de la fama sobre la actividad crítica de Clarín, solo la segunda clase de crítica era apreciada y verdaderamente aceptada por el famoso realista español.

El otro rasgo esencial de la crítica clariniana es un tipo de idealismo estético, relacionado con el quijotismo tradicional, elemento constitucional de la metafísica de la cotidianeidad. El quijotismo, como un comportamiento humano o una actitud original hacia la vida, ha marcado y sigue marcando todas las esferas del arte, especialmente la literaria, por ser El Quijote una obra clásica de Literatura Universal, actual e inspirativa en todos los tiempos. La relación de Clarín y Cervantes, o mejor dicho del quijotismo, no está tan clara y aparece solo por debajo de la evidencia textual en sus obras más conocidas, como La Regenta (1884-1885), Su único hijo (1891), la novela corta Doña Berta (1892) u otras obras de la prosa clariniana. Estas obras, aunque contienen algunas referencias cervantinas, 
no son diálogos literarios del corte post-cervantino o post-quijotesco (tan obvios en la novelística galdosiana) (Alfani 2005: 18). El quijotismo tiene una connotación mayoritariamente negativa en la novela realista española, siendo sinónimo del idealismo incurable, una enfermedad característica de la nación española en su desarrollo histórico.

Este concepto se relaciona con otro, contemplado y teóricamente engendrado precisamente por Clarín, especialmente en la época tardía de su actividad crítica. Se trata del concepto titulado el espíritu nuevo, o "una reacción idealista contra las limitaciones del positivismo y del materialismo y, así pues, una verdadera preocupación creciente por lo desconocido y por el misterio" (Lissorgues 1996: 259). Los escritos críticos clarinianos de la última época (1889-1901) posibilitan una lectura esencialmente espiritual y marcada por el concepto citado, contextualmente percibido como un avance en la tolerancia universal, progreso unido a un espíritu aperturista, tan ajeno al catolicismo español de la época (Lissorgues 1996: 262).

Estos tres rasgos pertenecen a diferentes épocas de la crítica literaria concebida por Leopoldo Alas, dominando no solo sobre el discurso crítico, teórico y estético dedicado a la obra de los nombres más representativos del realismo español, sino sobre los diálogos literarios actuales durante las dos últimas décadas del siglo XIX.

\section{Leopoldo Alas Clarín y Emilia Pardo Bazán: historia de amistad y desdén}

Podemos distinguir dos etapas en la crítica clariniana dedicada a la obra de Emilia Pardo Bazán (1851-1921): la primera, que comprende el tiempo del auge del naturalismo en la novela española (1881-1887); y la segunda, que abarca los años 1889-1901, cuya característica principal será el influjo del espiritualismo ruso, psicologismo e idealismo en la crítica clariniana (Sotelo Vázquez 2002: 162). La escritora coruñesa fue una constante obsesión de Clarín, especialmente en la última década del siglo, cuando las tendencias naturalistas ya no influían tanto en la producción literaria española y otras tendencias dominaban la novela finisecular española. Estamos de acuerdo con Ermitas Penas (2003: 10) en que esta obsesión resulta curiosa porque "es más que probable que la gallega y el asturiano nunca llegasen a conocerse". A pesar de este hecho Alas y Pardo Bazán siempre tuvieron una relación profesional "a distancia”, llena de respeto mutuo y con considerables elogios verbales y escritos de los dos sistemas literarios. 


\subsection{La primera época}

La primera reseña clariniana sobre la obra de la Pardo Bazán fue la dedicada a su novela Un viaje de novios (1881), incluida en el ensayo de Alas escrito en co-autoría con Armando Palacio Valdés, titulado La literatura en 1881 (1882). El rasgo principal de esta reseña es la objetividad, tan característica de este primer periodo de su actividad crítica. Clarín comienza destacando el gran talento y el potencial creador de la autora, su capacidad de escribir una novela genial y de acompañar sus novelas de un texto crítico y explicativo en forma de prefacio o postfacio, cuyas páginas sirven de apoyo a la teoría novelesca original. Esta reseña consta de dos partes: la primera, introductoria, trata la capacidad y el talento de la escritora, los elementos originales de su obra; la segunda, analítica y más importante, contiene un análisis concreto y minucioso de los elementos estilísticos, del contenido, de la estructura novelesca y los personajes (Penas 2003: 14). Presta especial atención el crítico a la cuestión del naturalismo y al concepto teórico de la novelística pardobazaniana:

[y] ya que hablo del naturalismo, me haré cargo de lo que dice la autora de Un viaje de novios en el prólogo, en que explica su manera de ser naturalista. No me parece exacto el concepto que de la nueva escuela ha formado, por más que lo considero mucho menos defectuoso que el que suelen tener otros literatos de España, que han tratado y siguen tratando esta cuestión con una ligereza y con una falta de datos que darían risa si no dieran vergüenza. La señora Pardo Bazán, discreta siempre, ha visto mejor que los más; pero no ha querido verlo todo. El naturalismo francés es precisamente el verdadero, el legítimo, el que tiene la clave, el que da la norma; el naturalismo español, a que ella se acoge, apenas acaba de nacer, y su existencia es todavía tan precaria que los más niegan aún que viva. (Alas Clarín 2003g: 42)

A pesar de este fragmento afirmativo en cuanto al sistema teórico de la escritora, Clarín a continuación analiza los aspectos naturalistas de la novela, acentuando los elementos no pertenecientes a esta tendencia literaria. Las únicas imperfecciones que encuentra en la novela se refieren a la composición y a algunos episodios en los que participan los personajes. Ya en esta reseña, tan temprana en la historia de la crítica literaria, se nota una tendencia hacia el apoyo abierto y la reafirmación del talento pardobazaniano y su actividad literaria. El análisis termina con un fragmento elogioso y optimista, en el que Clarín demuestra su 
capacidad de prever las tendencias futuras del desarrollo de la literatura realista española:

[e]n resumen. La Sra. Pardo Bazán podrá ser uno de nuestros mejores novelistas, porque Un viaje de novios tiene ya el sello de los libros buenos que quedan, si bien por su defectuosa composición, la falsedad de uno de los caracteres principales, y ciertas galas inoportunas del estilo, no puede proponerse como modelo. Los muchos defectos de esta novela no son de los que revelan inopia de ingenio; en cambio, las bellezas revelan a un verdadero artista digno de su tiempo y del rico idioma castellano, que es el que maneja. (Alas Clarín 2003g: 46)

En uno de los textos más significativos de esta primera época del análisis de la obra pardobazaniana, "Prólogo a la segunda edición" de los artículos La cuestión palpitante (1883), Alas se convierte en el principal partidario de la estética naturalista en España y defiende el sistema teórico de su colega gallega. En la parte introductoria nos informa sobre la importancia y la posición del libro en la polémica literaria existente, siendo el libro que mejor expone la doctrina de la entonces nueva tendencia literaria:

[y]o aquí voy a limitarme, en tal respecto, a decir algo de lo que el naturalismo no es, reservando la mayor parte del calor natural para elogiar, como lo merece, a la señora que ha escrito el presente libro. Porque, a decir verdad, si para mí es cosa clara el naturalismo, lo es mucho más el ingenio de tan discreto abogado, que me recuerda a aquel otro, del mismo sexo, que Shakespeare nos pinta en El mercader de Venecia. (Alas Clarín 1989: 125)

Después de citar su opinión sobre el naturalismo y las características que no pertenecen a esta estética, Clarín se concentra en la obra y la importancia de Emilia Pardo Bazán para el naturalismo español. Aunque expresa su distancia hacia las mujeres involucradas en el mundo literario, no puede esconder su elogio de las mujeres intelectuales, como Concepción Arenal y Emilia Pardo Bazán. La segunda merece una posición especial dentro del mundo literario español porque "tiene una poderosa fantasía, ha cultivado las ciencias y las artes, es un sabio en muchas materias y habla cinco o seis lenguas vivas." (Alas Clarín 1989: 130). La escritora gallega es para Clarín una prueba de gran lectura entre los intelectuales y del interés para la espiritualidad contemporánea; también es católica, creyente, aficionada a las letras clásicas y las nacionales y suele recono- 
cer la contemporaneidad del naturalismo; y por fin, el último fragmento del texto representa un tipo de consuelo a la escritora, porque va a sufrir muchos ataques y comentarios malintencionados, pero según su consejo, no debería hacerles caso sino continuar con su actividad y promover lo "eterno femenino" que la literatura universal lleva en sus entrañas (Alas Clarín 1989: 133-134).

En la siguiente reseña, dedicada a la novela La Tribuna (1882) (El Día, 02/03/1884), Clarín analiza con todo lujo de detalles los elementos más generales de la novela, especialmente el personaje de la protagonista y los elementos naturalistas. En oposición a los postulados expuestos en el "Prólogo" de la novela, Alas clasifica esta obra dentro del grupo naturalista, destacando que la autora obviamente no era consciente del influjo naturalista (Penas 2003: 19). Un espacio especial tiene la valoración subjetiva de Clarín, que reconoce que a él le gustaban: las facultades reveladas por la autora en su obra; y los rasgos insignificantes a primera vista pero excelentes anuncios del gran talento pardobazaniano: "No llegará a ser entonces la mujer que escriba mejor en España, porque ya lo es; pero sí a rivalizar dignamente con las que hayan sido o sean más célebres literatas del reino." (Alas Clarín 2003d: 55).

En la crítica dedicada a la novela titulada El cisne de Vilamorta (1884) (El Globo. Diario ilustrado, científico y literario, 17/09/1885) Clarín ya habla de la autora coruñesa como una de las mejores novelistas españolas, perteneciente a la "nueva escuela", o sea, la naturalista. Se nota una clara continuidad en el análisis crítico clariniano, porque según el modelo ya realizado, las primeras páginas siguen quedando reservadas para elogios y valoraciones superpositivas de la autora:

[e]s Emilia Pardo uno de los españoles que más saben y mejor entienden lo que ven, piensan y sienten. Tratar con ella, siempre es aprender mucho; y así, en sus mismas novelas, donde menos quiere enseñar, lo que resalta más es el talento, la penetración, la claridad con que ve y expresa, la corrección con que dice, lo sabiamente que compone, la perspicacia con que observa. (Alas Clarín 2003a: 60)

Según Clarín, esta novela refleja de manera notablelas características principales de la obra novelesca pardobazaniana y los postulados del naturalismo español expuestos por la autora en La cuestión palpitante, siendo un modelo más perfecto que las novelas anteriores: "es obra más pensada, más canónica se pudiera decir; su composición es mucho más sabia; la unidad de la acción más patente" (Alas Clarín 2003a: 60). 
Una de las críticas más positivas e importantes sobre la escritora coruñesa es la dedicada a la publicación de Los pazos de Ulloa (1886) (La Opinión, 07-30/11/1886). Según Clarín, se trata de la mejor novela de Pardo Bazán, obra de un estilo cuidado, minuciosamente engendrada en la mente artística, de una trama interesantísima y con unos personajes complejos y psicológicamente profundizados, etc. La primera parte de la reseña se refiere al análisis del texto titulado "Apuntes autobiográficos", que precede a la novela. Clarín pone de manifiesto la intención estética de la autora y no la biográfica, en conformidad con el título del texto, y explica que son obvios los esfuerzos de la autora para alcanzar una suficiencia lectora y forjarse un estilo propio, a pesar de su condición femenina (Penas 2003: 22-23). En este sentido hay que destacar un nuevo elemento de la crítica dedicada a la obra de la autora coruñesa: la objetividad novelesca y la gran calidad de su producción:

[1]o que yo digo es que Emilia Pardo no quiere enseñarnos su espíritu en sus novelas, y para ello se abstiene de penetrar en la sustancia de las cosas; y a riesgo de parecer inferior a sí misma, publica libros de arte en que se le ve menos que en sus mismas obras críticas; es decir el peor defecto de un poeta, si no fuera que aquí se trata de un deliberado propósito. (Alas Clarín 2003e: 78)

Leopoldo Alas dedica solo la última parte de su texto a los aspectos concretos de la novela publicada, acentuando el lenguaje y el estilo originales, etc. Hace comparaciones de la novela con la Bucólica, sus temas, ambientes y específica narración, elemento "más exquisito de su ingenio y de su maestría artística" (Alas Clarín 2003e: 80). Entre la galería de los personajes novelescos la mayor atención de Clarín la ocupa el capellán Julián, que a pesar de echar sobre sus hombros la enorme carga de remendar la moral y la hacienda de los Ulloa, solo consigue verse en tentaciones y una verosimilitud aparente. Se trata, piensa Clarín, de un personaje bien pensado, con gran delicadeza y fina pasión poética.

La crítica de las novelas pardobazanianas de la primera época resulta positiva, elogiosa y afirmativa en cuanto a la ingeniosidad y el talento de la escritora, acentuando especialmente los personajes de los protagonistas novelescos, cuya minuciosidad descriptiva y evolutiva le impresiona. Según las palabras de Marisa Sotelo Vázquez (2002: 171), en la evolución de la obra de su colega gallega Clarín ve resultados extraordinarios en la observación de la naturaleza, del medio ambiente, aunque le reprocha la falta de profundidad en los asuntos espirituales 
y en los "intereses del alma". En este periodo se publicaron las novelas naturalistas pardobazanianas y los artículos agrupados bajo el título La cuestión palpitante. En la primera mitad de los años ochenta se lleva a cabo el diálogo sobre el naturalismo en la literatura española. Por eso, no es de extrañar que la idea predominante de Leopoldo Alas obviamente fuera el apoyo a la colega y la afirmación de un tipo específico del naturalismo español, denominado "el naturalismo espiritual", cuyos representantes eran no solo Pardo Bazán y Clarín sino sus colegas y amigos entre los escritores aficionados a la ideología liberal estética, literaria y social.

\subsection{La segunda época}

En la segunda etapa, el tono crítico clariniano de la obra de Pardo Bazán es radicalmente distinto, tomando una postura sarcástica no solo contra las obras sino contra la autora, especialmente en cuanto a los datos personales y el comportamiento social. En los primeros años el centro de la crítica clariniana son las novelas Insolación y Morriña.

En la revista Madrid Cómico (11/05/1889) publica Clarín, dentro de la serie titulada "palique", la primera de varias reseñas sobre esta fase de la obra novelística de la coruñesa. Avisando al público sobre la publicación de la novela Insolación (1888), Alas cree que merece la pena de ser notada y leída, aunque no se trata de la mejor de las novelas pardobazanianas, calificándola como una historia "pseudo erótica de la ilustre dama gallega" (Alas Clarín 2003b: 91), y sigue así:

[n]o es para mí doña Emilia uno de los escritores más profundos, ni de más corazón, ni más sinceros de España; ni tampoco de los artistas de más inventiva, fecundidad y gracia, pero sí de los más valientes, instruidos, discretos, elegantes en el decir y modernos en el pensar... en algunas cosas.

Esta novela obtuvo una valoración negativa especialmente en cuanto a la poética del realismo / naturalismo español, por carecer del sentimiento poético, y ser una pintura de la sensualidad más pedestre y gastada. El amor, según Clarín, como tema principal, no es más que mera vulgaridad, necedad, pobreza de espíritu, la perversión inútil, caprichosa, sin enseñar nada, ni doctrinal ni estéticamente.

El texto crítico sobre la novela Morriña (1889) (Madrid Cómico, 9-23/11/1889) contiene un análisis habitual de la estructura novelesca, de los personajes y del estilo empleado, pero se nota un tono diferente, lleno de ironía y mala intención. El objeto de la crítica es la productividad 
irreal de la novelista, que ha publicado dos novelas en un breve periodo de unos meses (Penas 2003: 28).

A continuación de su actividad crítico-literaria, Clarín dedica varios "paliques" a las novelas pardobazanianas - principalmente a Una cristiana (1890) y La prueba (1890). Mientras el foco de la crítica de la primera novela son los personajes y sus comportamientos, en la crítica de la segunda predomina el tema de la carencia del alma de su autora, porque se nota lo naturalista y no lo católico, para Clarín también imprescindible en la creación artística.

Leopoldo Alas pierde su postura objetiva cuando juzga (Madrid Cómico, 14/02/1891 y La Correspondencia de Madrid, 15/02/1891) la revista Nuevo Teatro Crítico, proyecto de la escritora coruñesa, donde publicó varios textos significativos para la esfera crítico-literaria del momento (Karanović 2018: 326). Estos textos pertenecen a los más subjetivos de Clarín, que aprovecha la ocasión para explicar implícita e indirectamente las causas de su mala comunicación y consecuentemente del ya proverbial diferente tono en la crítica dedicada a la escritora gallega:

(...) cuando doña Emilia un día sí y otro no, y me llamaba su hermano mayor (aunque soy algo más joven) y yo le ponía prólogo a los libros y la buscaba editor para ellos (La cuestión palpitante) y... la trataba, animarla con excesiva benevolencia, doña Emilia me regalaba sus obras acompañadas de sendas dedicatorias cariñosas y encomiásticas; pasó el tiempo, se creció la escritora gallega, empecé yo a pesar con más justicia el mérito de sus escritos y ella siguió enviándome sus libros... pero con dedicatorias menos expresivas; pasó más tiempo, publicó la Pardo Bazán novelas que me parecieron medianas, así lo dije, y doña Emilia continuó enviándome sus libros, pero sin dedicatoria; pasó más tiempo, tuve que decir a mi ilustre amiga algunas verdades amargas... y doña Emilia dejó de enviarme sus obras; pero permitió o mandó que me las remitiese el editor, y por último, después de algunas cuchufletas mías y de ciertos reparos a su modo de entender las palabras y las ideas... la señora Pardo Bazán cortó por lo sano, y ahora ni ella ni el editor me envían libros de esta eruditísima señora. No me parece bien el procedimiento. (Alas Clarín 2003f: 142-143)

Parece que la mayor parte de su crítica Clarín la dedica al análisis estilístico de los textos publicados en la revista citada. A pesar del tono crítico clariniano, se aconseja a Pardo Bazán la continuación de la actividad periodística y crítico-literaria, en la forma en que lo ha hecho o en otra. Con un considerable potencial sarcástico Clarín concluye que "la otra manera" será más conveniente en el futuro. 
Entre las últimas obras de Emilia Pardo Bazán, La piedra angular (1891) despierta el mayor interés de Alas, de lo que testimonia la reseña publicada en la revista El Lunes de El Imparcial (29/02/1892), calificándola como la inferior, resultado de todos los defectos de higiene espiritual, de la precipitación que se revela en las incorrecciones, de la falta de asimilación reflexiva y estética del objeto escogido, de la superficialidad en la trama novelesca, etc. (Alas Clarín 2003c: 152-153).

En los últimos años de su vida Clarín dedicó varios textos reseñando las publicaciones tardías de Emilia Pardo Bazán (El tesoro de Gastón, Cuentos, etc.) y trató de acentuar la diferencia en calidad literaria entre las novelas anteriores y las actuales, pálido reflejo de la fama literaria de antaño. Parece que los cuentos no merecieron ninguna valoración positiva por parte de Clarín, quien analizando las colecciones publicadas sentía la nostalgia por las novelas pardobazanianas, aunque fueran las de la última época, puesto que el crítico no creía en la autenticidad y verosimilitud de la autora en el campo de las narraciones breves.

En los últimos años de su actividad crítica (1895-1900) Clarín vuelve a la cuestión del naturalismo y su impacto en la literatura nacional de los años pasados. A diferencia de sus elogios escritos a principios de la década de los ochenta, Leopoldo Alas se convierte en un crítico de esta tendencia, cada día más aficionado a la literatura del llamado "realismo / naturalismo espiritual" o hasta a la literatura espiritual en general, basada en la tradición y la filosofía del idealismo estético y espiritual. Según la tendencia crítica sobre la obra tardía de la coruñesa, Clarín, ahora con una distancia cronológica expone sus juicios estéticos, por ejemplo, sobre el papel de la escritora en el desarrollo del naturalismo español. Para él, Pardo Bazán vulgarizó el darwinismo en España y falló en muchas interpretaciones de la ley natural, citando consecuentemente varios ejemplos opuestos a la concepción pardobazaniana del naturalismo.

\section{Conclusiones}

Parece que la visión de la actividad crítico-literaria clariniana ha sido mejor representada por Sergio Beser (1968: 341), para quien esta encaja en una duradera tradición europea del criticismo literario, cuyas raíces están tanto en la filosofía y estética alemanas como en la crítica francesa, pero sobre todo, en la tradición humanista y renacentista. Por tanto, dos principales coordenadas de la crítica literaria clariniana son el pensamiento idealista alemán y el positivismo historicista francés, aunque el tiempo y el espacio son exclusivamente locales - el ambiente nacional 
español. Su visión de la literatura y el arte literario resulta universal y europea, aunque marcada constantemente por fuertes características nacionales y locales (Karanović 2018: 327). En los textos críticos dedicados a la obra de Emilia Pardo Bazán, podemos detectar fácilmente dos tipos de reseñas y críticas clarinianas, favorables y desfavorables, o sea positivas y negativas. En la primera fase el foco está en los elementos innovadores de la obra pardobazaniana, analizados según los postulados de una estética literaria muy cercana al quijotismo espiritual, que mezcla en este caso la moralidad individual, altos valores literarios y un tipo de idealismo y esteticismo constante y palpable. En la segunda fase nos encontramos con un tono crítico diferente y una revalorización de los elementos literarios ya evaluados o un nuevo sistema crítico, más exigente y con nuevos requisitos estético-literarios. ¿Cuáles son las posibles causas del cambio que efectúa Clarín en su actividad crítica en este campo? Durante su trayectoria crítica Alas sigue una dirección estable y previsible, resultado de su formación intelectual y el sistema estéticoespiritual (desde el krausismo y liberalismo artístico en la juventud hacia el idealismo radical de la última época). Sus postulados tardíos se basan en causas ajenas a la estética literaria, extraliterarias, o mejor dicho, en los prejuicios y relaciones personales con los autores.

\section{BIBLIOGRAFÍA}

Alas Clarín, Leopoldo. "Prólogo de la segunda edición". Emilia Pardo Bazán. La cuestión palpitante. Edición, Estudio introductorio, notas y Apéndice de José Manuel González Herrán, Barcelona: Editorial Anthropos / Santiago de Compostela: Universidad de Santiago de Compostela, 1989: 123-134. Impreso.

Alas Clarín, Leopoldo. "El cisne de Vilamorta (Novela por doña Emilia Pardo Bazán)". Ermitas Penas. Clarín, crítico de Emilia Pardo Bazán, Santiago de Compostela: Universidade de Santiago de Compostela, Servicio de Publicacións e Intercambio Científico, Lalia, Series Maior, 17, 2003a: 59-63. Impreso.

Alas Clarín, Leopoldo. “Insolación (Palique)". Ermitas Penas. Clarín, crítico de Emilia Pardo Bazán, Santiago de Compostela: Universidade de Santiago de Compostela, Servicio de Publicacións e Intercambio Científico, Lalia, Series Maior, 17, 2003b: 91-92. Impreso. 
Alas Clarín, Leopoldo. "La piedra angular (Novela por doña Emilia Pardo de Bazán)”. Ermitas Penas. Clarín, crítico de Emilia Pardo Bazán, Santiago de Compostela: Universidade de Santiago de Compostela, Servicio de Publicacións e Intercambio Científico, Lalia, Series Maior, 17, 2003c: 151-157. Impreso.

Alas Clarín, Leopoldo. "La Tribuna (Novela original de doña Emilia Pardo Bazán)”. Ermitas Penas. Clarín, crítico de Emilia Pardo Bazán, Santiago de Compostela: Universidade de Santiago de Compostela, Servicio de Publicacións e Intercambio Científico, Lalia, Series Maior, 17, 2003d: 51-55. Impreso.

Alas Clarín, Leopoldo. "Los pazos de Ulloa (Novelistas españoles contemporáneos)". Ermitas Penas, Clarín, crítico de Emilia Pardo Bazán, Santiago de Compostela: Universidade de Santiago de Compostela, Servicio de Publicacións e Intercambio Científico, Lalia, Series Maior, 17, 2003e: 67-81. Impreso.

Alas Clarín, Leopoldo. "Nuevo Teatro Crítico". Ermitas Penas. Clarín, crítico de Emilia Pardo Bazán, Santiago de Compostela: Universidade de Santiago de Compostela, Servicio de Publicacións e Intercambio Científico, Lalia, Series Maior, 17, 2003f: 139-148. Impreso.

Alas Clarín, Leopoldo. "Un viaje de novios (Novela de la señora doña Emilia Pardo Bazán)". Ermitas Penas. Clarín, crítico de Emilia Pardo Bazán, Santiago de Compostela: Universidade de Santiago de Compostela, Servicio de Publicacións e Intercambio Científico, Lalia, Series Maior, 17, 2003g: 39-47. Impreso.

Alfani, María Rosaria. El regreso de don Quijote (Clarín y la novela). Salamanca: Editorial Ambos Mundos, Biblioteca Filológica, 2005. Impreso.

Beser, Sergio. Leopoldo Alas, crítico literario. Madrid: Gredos, Biblioteca Románica Hispánica, 1968. Impreso.

Karanović, Vladimir. Španska književnost realizma. Beograd: Filološki fakultet, 2018. Štampano.

Lissorgues, Yvan. El pensamiento filosófico y religioso de Leopoldo Alas, Clarín (1875-1901). Presentación de Laureano Bonet, Oviedo: Grupo Editorial Asturiano, 1996. Impreso.

Penas, Ermitas. "Prólogo". Ermitas Penas. Clarín, crítico de Emilia Pardo Bazán, Santiago de Compostela: Universidade de Santiago de Compostela, Servicio de Publicacións e Intercambio Científico, Lalia, Series Maior, 17, 2003: 9-36. Impreso.

Sobejano, Gonzalo. Clarín en su obra ejemplar. Madrid: Editorial Castalia, Colección Literatura y Sociedad, 1991. Impreso. 
Sotelo Vázquez, Marisa. “Clarín y Emilia Pardo Bazán”. Antonio Vilanova \& Adolfo Sotelo Vázquez (Eds.). Leopoldo Alas "Clarín" (Actas del Simposio Internacional, Barcelona, abril de 2001), Barcelona: Universitat de Barcelona, 2002: 161-185. Impreso.

\title{
THE AESTHETIC IDEALISM IN THE CRITICAL-LITERARY TEXTS OF LEOPOLDO ALAS CLARÍN: A CRITICAL LOOK AT THE WORK OF EMILIA PARDO BAZÁN
}

\begin{abstract}
Summary
One of the essential elements of the critical activity of Leopoldo Alas Clarín (1852-1901) is pragmatism, which leads him to practice two kinds of literary criticism: 1 ) the one that does not depend on the writers mood but on the works or the analyzed authors, which can be called the "negative criticism" since those were books that lacked of artistic value and authors who were unable to escape vulgarity, that is, a type of parasites of literary life, criticism whose main element was mockery, attack, "hygienic and police criticism"; and 2) the one that includes a thorough study, contains clear elements of sympathy and liking towards the analyzed authors, so consequently it can be called "positive criticism". Despite the fame about Clarín's critical activity, only the second type of criticism was appreciated and truly accepted by the famous Spanish realist.

Critics and novelists of Spanish realism, among which we highlight Leopoldo Alas Clarín, present a singular importance in the field of receiving an aesthetic idealism, coming from pre-modern quixotism, since with his literary and critical-literary works show an evolutionary path from the mere status pro or against the new literary tendencies of realistic writers to an aesthetic and spiritual idealism, characteristic for the last years of the 19th century.

El objetivo principal de presente artículo es identificar, interpretar y explicar la presencia y la recepción del idealismo estético y su evolución en los textos crítico-literarios clarinianos dedicados a las obras de Emilia Pardo Bazán.

The main objective of this article is to identify, interpret and explain the presence and reception of aesthetic idealism and its evolution in the Clarín's critical-literary texts dedicated to the works of Emilia Pardo Bazán.
\end{abstract}

Keywords: Leopoldo Alas Clarín, Emilia Pardo Bazán, 19 ${ }^{\text {th }}$ century, literary criticism, Spanish realism. 